\title{
PRIMA-1 Analog APR-246
}

National Cancer Institute

\section{Source}

National Cancer Institute. PRIMA-1 Analog APR-246. NCI Thesaurus. Code C85465.

A methylated derivative and structural analog of PRIMA-1 (p53 re-activation and induction of massive apoptosis), with potential antineoplastic activity. Upon administration, PRIMA-1 analog APR-246 covalently modifies the core domain of mutated forms of cellular tumor antigen p53 (p53) through the alkylation of thiol groups. These modifications restore both the wild-type conformation and function to mutant p53, which reconstitutes endogenous p53 activity, leading to cell cycle arrest and apoptosis in tumor cells. This agent may work synerg istically with other antineoplastic agents. p53, a tumor suppressor and transcription factor normally activated upon DNA damage, is frequently mutated and overexpressed in cancer cells; it plays a key role in both DNA repair and the induction of apoptosis. 